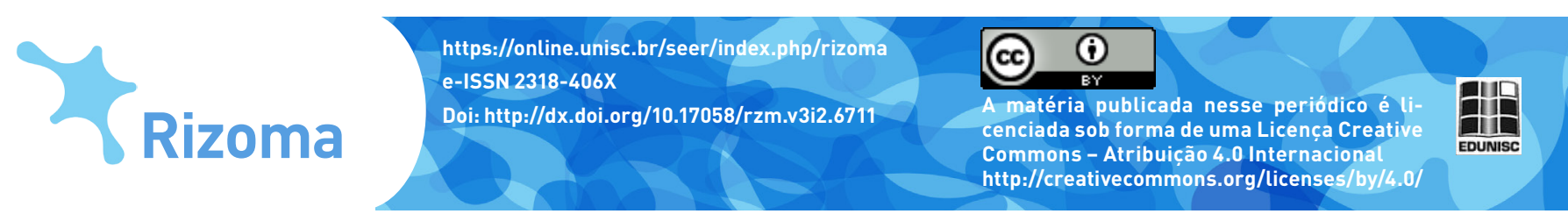

\title{
El salón de clases como espacio de ne- gociación entre prácticas tradicionales y emergentes de lectura Etnografía de la experiencia de un grupo de jóvenes universitarios
}

\section{Resumen}

Este artículo reseña los principales resultados de una etnografía de las prácticas y representaciones tradicionales y emergentes de lectura en jóvenes universitarios de comunicación de una universidad pública en la Ciudad de México, a partir del uso generalizado de diversas plataformas y dispositivos digitales dentro y fuera del aula.

Palabras clave: Jóvenes; lectura; prácticas tradicionales; prácticas emergentes; dispositivos digitales.

\section{Resumo}

Este artigo apresenta os principais resultados de uma etnografia das práticas e representações tradicionais e emergentes de leitura em jovens universitários de comunicação de uma universidade pública na Cidade do México. O estudo se dá a partir do uso generalizado de diversas plataformas e dispositivos digitais dentro e fora da sala de aula.

Palavras-chave: Jovens; leitura; práticas tradicionais, práticas emergentes; dispositivos digitais.

\footnotetext{
Abstract

This article presents the main results of an ethnographic study of the traditional and emergent practices and representations in the act of reading by young college students of Communications at a public university in Mexico City. This study focuses on the widespread use of digital platforms and gadgets inside and outside the classroom.
}

Rosalía Winocur ${ }^{1}$
${ }^{1}$ Doctora en Antropología Social. Profesora e investigadora en el Departamento de Educación y Comunicación de la Universidad Autónoma Metropolitana de México. 
Keywords: Youngsters; reading; traditional practices; emergent practices; digital gadgets.

\section{Introducción}

¿Cómo leen los estudiantes universitarios? ¿Cómo se ubican, o reubican las prácticas tradicionales de lectoescritura en el constante transcurrir del chat, el posteo, la publicación y el clic?, ¿cómo se reciclan, traslapan o resignifican los modos de leer emergentes con los con los tradicionales?, ¿cuándo y con quién leen?, ¿cómo organizan y relacionan la información que leen?,¡cuáles son los procesos y las estrategias que desarrollan para comprender el significado y reconstruir el sentido de los textos que leen?, ¿cuáles son las diferencias de las prácticas de lectura en pantalla y en papel?, ¿cuáles son los contenidos más habituales que circulan y se socializan?, ¿qué tipo de continuidades y discontinuidades se producen entre las prácticas emergentes y tradicionales en diversos soportes y temporalidades.

Para responder estos interrogantes, se llevó a cabo en el año 2014 una etnografía de las prácticas de lectura de un grupo de estudiantes de comunicación en la Ciudad de México. En la perspectiva teóricometodológica ${ }^{2}$ que sustentó la investigación, focalizamos la atención en la experiencia de los jóvenes recuperando los significados y representaciones de sus prácticas de lectoescritura. Igualmente asumimos que la lectura y escritura en la Red son prácticas indisociables, heterogéneas y polisémicas en el espacio biográfico, y que el desafío no es realizar un inventario de las mismas sino comprender su diversidad y significación en el complejo entramado del espacio biográfico de los jóvenes. Razón por la cual, al observar sus prácticas de lectoescritura en distintos soportes físicos y virtuales, nos concentramos más en dar cuenta de los traslapes y negociaciones, que en las diferencias y conflictos, y privilegiamos la indagación de las continuidades y discontinuidades por encima de la descripción de las fracturas y dispersiones. También aceptamos desde el punto de vista epistemológico como posible, y no excluyente, que exista un imaginario social sobre el valor de la lectura y los libros, que sigue siendo dominante entre los jóvenes, y que al mismo tiempo convive sin conflicto con unas prácticas de lectoescritura compulsivas en Internet que aparentemente lo "desmienten".

Los modos de lectoescritura emergentes que practican los jóvenes en Internet, y su convivencia complementaria, paradójica, reconocida o negada con los modos tradicionales, fueron situados para su observación y análisis, en el contexto de las experiencias sociales, afectivas, lúdicas, y cognoscitivas compartidas con sus referentes significativos (cercanos y lejanos, mediáticos y virtuales) en las redes sociales.
${ }^{2}$ La estrategia metodológica consistió en combinar la reconstrucción de trayectorias biográficas mediáticas y digitales (a través del recurso de la entrevista en profundidad y la autobiografía), con la observación de las prácticas de lectoescritura en la Internet en varios soportes (celulares inteligentes, tabletas, computadoras, etc.) y plataformas virtuales (Facebook, Twitter, blogs, Youtube, etc.). Para la observación de las prácticas de lectoescritura se seleccionaron a 26 jóvenes universitarios entre 18 y 29 años de la Carrera de Comunicación Social de la UAM Xochimilco. 


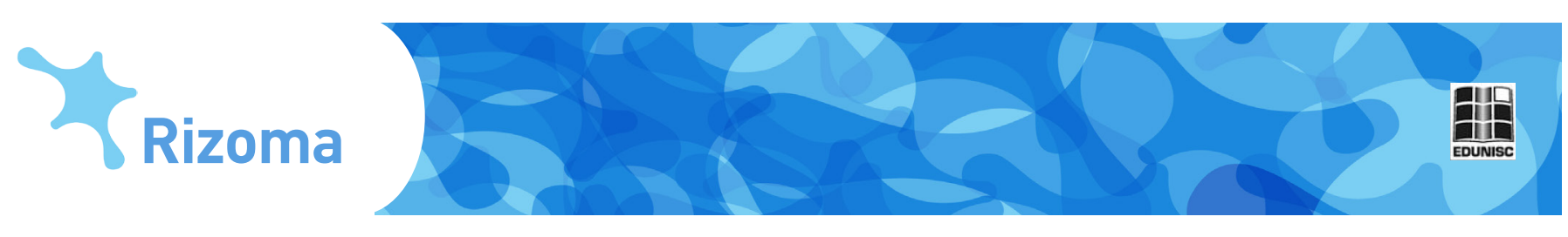

\title{
Uso pragmático de todas las plataformas, soportes y recursos físicos y digitales
}

Aunque el desplazamiento desde los libros, las enciclopedias y las bibliotecas hacia los buscadores de Internet y las redes sociales es masivo y generalizado, al momento de resolver las tareas escolares o trabajos de investigación, los estudiantes se enfrentan con diversos problemas para validar la información o elegir entre muchas posibles opciones de contenidos en la Red. De ahí que algunos todavía recurren a la biblioteca cuando no encuentran el texto en Internet, o al profesor para les recomiende expresamente dónde ubicarlo dentro o fuera de la Red. En cuanto a los textos escolares, a la gran mayoría de los estudiantes les parece incómodo y desagradable leer en PDF o formatos digitales y optan por realizar las lecturas largas en fotocopias, impresiones del PDF o libros impresos. Esto resulta interesante cuando lo comparamos con la cantidad de textos cortos que leen y reproducen en formatos digitales, pero la comprensión de los textos más largos y complejos se facilita en los formatos impresos. En síntesis, recurrir a un PDF para leer un libro académico, no es una opción definitiva frente al texto impreso sino una operación pragmática cuando no se dispone del libro o de las fotocopias.

Prefiero impreso. Siempre. Pero hay libros que no se encuentran impresos, que es cuando los busco en PDF. Por lo regular es cuando recurro a la pantalla, pero prefiero el libro porque puedo consultarlo (...) cuando quiera volver a leerlo, es más fácil para mí encontrar en donde porque ya doblé la hoja, o porque ya tiene anotaciones, que en el digital que es como de “argh, ¿dónde era?”. (Samantha, 21 años)

Dentro de la constante diversificación de tareas simultáneas en la Red, la lectura tradicional no pueda ser practicada ni compartida mientras se revisa Facebook, se leen otros artículos o se hacen otros trabajos:

\begin{abstract}
Yo creo que siempre es bueno leer solo. (...)Y la lectura, creo que es un ejercicio de reflexión individual. O sea, tal vez después de leer puedes ir con una persona que leyó lo mismo y discutir el texto pero creo que sobre todo la literatura es lo que debe leer solo. Tal vez textos académicos, textos informativos, noticias, de prensa... tal vez sí es más factible leerlos en grupo porque permite una discusión al momento, además de la necesidad de discutir al momento un asunto actual (Antonio,18años)
\end{abstract}

En el testimonio anterior, es interesante observar cómo las noticias son los textos que mejor se adaptan al lenguaje de las redes sociales porque nacen, se reproducen, viajan y mueren con la misma velocidad que los intercambios que se producen cotidiana y permanentemente a través de todos los dispositivos digitales. Las redes sociales junto con las aplicaciones que permiten hablar, o mandar mensajes de manera gratuita (como WhatsApp), son los medios más usados para resolver la organización del trabajo en equipo. El uso de Facebook para coordinar y asignar tareas para los trabajos en equipo, y el de Google Drive y Dropbox para almacenar y compartir documentos en 
tiempo real, son quizás los cambios más importantes en la forma de organización del trabajo escolar. No obstante, si bien su uso está muy generalizado y les resulta cómodo, no implica que sea eficiente:
${ }^{3}$ Albarello, F. (2011). Leer-navegar en internet: las formas de lectura en la computadora. La Crujía, Buenos Aires. P. 232.

Hemos intentado eso de: -termino mi parte, la envio al grupo de Facebook y ya las vamos juntando. (...). pero nos hemos dado cuenta que no nos resulta, que no es efectivo. Hernán (25 años)

De ahí que estas aplicaciones no sustituyen las reuniones físicas para dividirse las tareas antes de una entrega o trabajo final, pero son claves para convocarlas y distribuir las tareas. Es de hacer notar que la preferencia por reunirse presencialmente, es coherente subjetivamente con la preferencia de leer en impreso por la sensación de una mayor apropiación de la información en la relación cara a cara. Aparentemente los estudiantes sienten una mayor percepción de realidad y materialidad, cuando se vinculan personalmente a los compañeros de equipo, o leen un libro impreso, que cuando se trata de lo mismo pero digitalizado.

La lectura digital e impresa, conviven con múltiples fuentes y plataformas a lo largo de un día "normal" en la vida de los universitarios. Recuperan instrucciones para hacer la tarea a través de correos electrónicos enviados por los profesores, realizan lecturas derivadas de esas instrucciones en ambos tipos de soportes, comparten la interpretación y significación de sus experiencias a través del celular o la tableta, reproducen contenidos impresos a formatos digitales que son nuevamente impresos, los impresos son re-apropiados y reconstruidos a través de búsquedas en internet, y las textos digitales se imprimen o se buscan en la biblioteca para fotocopiar.

Me gusta más tener el libro impreso porque puedo subrayar, puedo hacer anotaciones, este... y siento que... pues no sé, estarlo tocando, la textura, es, como estar más cerca del libro. Adentrarte más. El de Malcolm lo fotocopié, pero venía incompleto. Entonces tuve que recurrir al PDF que nos envió la profesora, pero sólo para completar lo que hacía falta. Y sí era un poco más complicado leerlo porque en la computadora, la luz de la computadora, me lastimó, entonces sí. Es complicado. (Samantha, 21 años)

En ese sentido coincidimos con Albarello (2011), que para el caso de los textos universitarios "La pantalla no genera un tipo de lectura totalmente novedosa, sino que existe una remediación de la lectura que toma elementos de la lectura del impreso y genera otro nuevos, pero todos funcionan de forma complementaria de acuerdo con determinadas metas y estrategias de lectura, de naturaleza cambiante y vinculadas con necesidades diversas de información, comunicación y entretenimiento." $(2011: 168)^{3}$.

En el siguiente ejemplo se puede advertir claramente el tipo de negociación que se produce entre diversos soportes, lugares de referencia y recursos institucionales a la hora de validar, ampliar o comprender la información. Debido a la naturaleza de las lecturas que hacen con mayor frecuencia, textos universitarios que implican un grado importante de complejidad, es común que accedan a Internet para complementar los temas que están tratando, ya 
sea informándose con mayor detalle sobre determinado autor, o rastreando algún video que ilustre de manera gráfica el tema. El recurso más usado cuando hay dudas o dificultades para comprender un texto es tratar de aclarar su significado realizando búsquedas en internet, pero este recurso resulta muchas veces insuficiente, entonces se recurre al compañero, al libro y en última instancia se le pregunta al profesor/a:

Cuando no entiendo las cosas, por lo regular busco en Internet o busco en otros lugares más bibliografía acerca de ese tema. Si es algo del autor y de plano no le entiendo, pues entonces sí busco alguna explicación de algún teórico sobre ese teórico, o sobre lo que quiso decir, o si no, pues ya de plano le pregunto a Antonio o me espero hasta el otro día a ver qué dice la profesora de eso. (Jimena, 20 años)

No pensamos que este orden implique algún tipo de jerarquías, sino que forma parte de una estrategia de utilización de todos los recursos disponibles para reconstruir el sentido del texto, donde Internet es el más rápido y está todo el tiempo disponible, pero puede resultar el menos confiable, mientras que el profesor/a y los libros siguen siendo las fuentes más autorizadas. En el caso de Antonio, la calidad en la redacción y la argumentación, así como la importancia otorgada al autor o a la fuente, son criterios para validar los datos de los sitios de consulta. Algunos señalan que dichos criterios provienen de la práctica escolar y las orientaciones que reciben de los profesores, y también de su propia experiencia adquirida en la navegación:

Cuando un texto está muy mal redactado y con muy mala ortografía... veo un blog así y digo "qué asco" o sea, no. Esto no, o sea, lo leo pero dices: "no". Hasta duele leerlo y dices: "no, no, no veo como una argumentación sólida... no" Entonces eso lo haces a un lado. Ya después busco algo más que parezca un poco más sólido, o sea, que hayan ciertos argumentos, que no sea siempre... pues perogrulladas en las que dicen: "esto es asi porque asi”" o sea cosas que ya se saben, sino que... qué más puede ofrecer cierto sitio. (Antonio, 18 años)

En el siguiente ejemplo, vemos como la consulta de la popular Wikipedia, muy utilizada al inicio de la carrera, se ha relativizado aunque continúa siendo una estrategia de reducción de complejidad que les permite ordenar la búsqueda a partir de los links que poseen todas las entradas que los van derivando hacia otros sitios y lugares:

Por lo regular antes buscaba las cosas en Wikipedia y ahí me quedaba, pero últimamente sí es Wikipedia (...) pero para darme una idea más o menos de lo que me están pidiendo, de lo que trata el tema y ya después es buscar en otros sitios. O sea, anteriormente era lo primero que encontraba y se escuchaba medio claro ya lo agarraba y eso lo leía ¿no? (Jimena, 20 años)

Otro criterio de baja confiabilidad reside en lo que resulta sospechoso de estar vinculado o producido, directa o indirectamente por "el poder": 
$Y$ también consultar los medios que se conocen por ser afines al sistema o al poder, para comparar lo que se está diciendo... saber qué información es veraz; generar un criterio. Al final de cuentas la información es casi la misma, lo que cambia es cómo se estructura para darle ese sentido subjetivo a lo objetivo de lo que está redactado; la noticia o no sé. (Antonio, 18 años)

La mayoría también reconoce que la universidad ha jugado un papel formativo clave al respecto, al brindarles herramientas de análisis de la información que les permiten decidir qué contenidos son válidos o útiles para los fines de las búsquedas:

Yo diría que sí, porque aqui nos han enseñado mucho el hecho de que uno tiene que hablar con fundamentos. Todos tienen una opinión respecto a todo, pero no todas las opiniones están bien fundamentadas. Entonces lo que ha cambiado es que al buscar la información trato de que esté bien fundamentada, que sea más puntual y, en algún sentido, válida. (Hernán, 25 años)

No existe un método consciente de sistematización de la información. Los hipervínculos que parten de un texto digital o impreso se convierten en información agregada que suman referencias a la lectura pero no formarán parte de la "bibliografia" explícita o registrada del lector. Al parecer, esa lectura hipertextual no solo se da por una necesidad de enriquecimiento de la lectura tradicional, sino que también tiene un sentido lúdico. El salto de un texto a otro rompe con la idea de que para comprender un texto se debe ir del principio al final, y este "desorden" no conduce necesariamente a la anarquía conceptual, o a un déficit de comprensión, como se puede ver, en las tareas que hicieron sobre una lectura de Gabriel García Márquez en el contexto del taller de escritura del módulo de prensa.

\section{Lecturas fragmentadas y expandidas}

Si bien hasta no hace mucho, los jóvenes tenían en el día a día una serie de interacciones con los libros, los periódicos, sus maestros e incluso con la radio, la televisión y el cine, que sumaban elementos a sus lecturas y que se incorporaban en la síntesis conceptual que hacían de los textos, estas referencias eran más homogéneas y provenían de fuentes autorizadas. Ahora la cantidad de información que se mezcla en la creación de conceptos es inmensurable, el origen de la red de relaciones que componen las ideas se hace cada vez más difícil de rastrear. En estas nuevas condiciones donde se ejerce la lectura, hemos podido comprobar, al igual que otros estudios (Albarello, 2011; Andrade, 2007; Castellanos, 2001; Chartier, 1997; Chartier, 2010; Domínguez y Rodríguez, 2005; Friera, 2002; Igarza, 2011; Rey, 2009; que cada vez se lee más rápido, por menos tiempo, y se busca la diversificación de las fuentes y sus medios. Estas prácticas se manifiestan como lecturas fragmentadas y expandidas. Respecto al primer tipo, los estudiantes hacen lecturas online que los llevan a dar "saltos" de un texto a 
otro constantemente, a veces para realizar búsquedas que complementen la actividad principal, otras veces para terminar en un lugar muy alejado del que comenzaron. Es muy común llegar a un texto en línea -ya sea porque se buscó con precisión o porque se llegó a él en el transcurso de los clicsabrirlo, leer unas cuantas líneas (las suficientes como para saber si interesa o no) y ponerlo en una lista de espera (dejar la pestaña abierta para retomarla más tarde, poner el link en una lista de lectura, descargar el texto y archivarlo, etc.). Esa lista de descubrimientos, de textos acumulados, es posible retomarlos en cualquier momento y que cuando así sea, se lean otras líneas y se pase a algún otro texto, que nuevamente podría estar o no relacionado con la lectura de origen.

"La lectura también ha cambiado. Anteriormente en mi explorador tenía la opción de abrir tal cual las pestañas que dejaba cuando cerraba y esto me hacía un sinfín de pestañas que no leía y sólo me estorbaban, ahora si algo me interesa lo pongo en marcadores y voy alternando mis lecturas. Puedo estar leyendo un PDF en uno de mis monitores, en el otro intercalar pestañas en dos artículos que estoy leyendo y poner en otra pestaña un video. (Karina, 26 años)

La lectura fragmentada sería entonces el tipo de lectura que admite la "dispersión" a través del multitasking, como principal insumo para ser productivo en la red. En una lectura fragmentada los textos no se dejan inconclusos necesariamente por falta de interés, sino por la necesidad de cambiar de tema o de espacio y en cierto sentido esto tiene que ver con la rapidez con la que cambian los contenidos y circulan en la red y la necesidad de ir de acuerdo con estos cambios, como si fuera una medida de adaptación de los jóvenes a las condiciones del espacio virtual. Aunque es difícil reconocer en qué momento toda esta información hace síntesis, o genera algún tipo de conclusión, los jóvenes no la consideran desechable ni azarosa, sino potencialmente reutilizable en algún momento, o al igual que con cualquier objeto físico, susceptible de ser coleccionable. Es decir, guardar todos los links y textos, por el simple placer de poseerlos.

"El cambio más drástico se dio a partir de Google. Todo (y cuando digo todo, es ABSOLUTAMENTE TODO) lo busco en google. (...) Por lo mismo, la lectura también ha cambiado. En ocasiones encuentro información y la almaceno en carpetas de favoritos en la red para después darles lectura". (Bernardo, 28 años)

El segundo tipo de lectura, que hemos denominado expandida, refiere a la diversificación y el consumo de las fuentes de consulta (textos, imágenes, videos, etc.) que logran enriquecer el texto del que parten y ampliar sus límites. La particularidad de la lectura expandida con respecto a la lectura fragmentada, es que las búsquedas de un texto son referencias que complementan la lectura de origen y que se incorporan inmediatamente a ésta, en cambio, en la lectura fragmentada es más difícil reconocer el momento de génesis o de síntesis de la información. En una lectura expandida se hace evidente la hipervinculación 
de los mundos físicos y digitales. Incluso quienes disfrutan más de la lectura en soportes impresos, hacen búsquedas de referencia en línea y van alternando la lectura en pantalla con la lectura en impreso.

La posibilidad de hacerlo al instante, de tener a la mano la llave para entender cómo es un lugar del que se habla, cómo se ve la gente de ese sitio, cuál era la familia de tal o cual personaje real, el background histórico, hace que leer sin el apoyo de un buscador de internet sea una circunstancia que le hace a uno pensar que "algo falta". No ocurre esto con novelas o temas que no requieren de un marco de referencias más complejo, aunque también es placentero poder armar la imagen de un autor, conocer sobre la recepción de una obra y leer incluso reseñas sobre ella. (Isadora, 29 años)

El hábito más común para compartir materiales de lectura impresos conserva rasgos de las prácticas de socialización de los soportes predigitales: regalan libros, los prestan, los toman de bibliotecas personales de conocidos y muy excepcionalmente los adquieren en librerías cuando cuentan con los medios para hacerlo. Asimismo, todos los testimonios citados a continuación hablan de una fuerte conexión emocional con el libro impreso a partir de referentes afectivos muy importantes en la vida de los estudiantes, como los padres, tíos, madrinas y los abuelos:

Entre muchas de sus novelas elegi "La Mala Hora" por ser una de las novelas favoritas de mi abuelo. (Beatriz, 23 años)

García Márquez es uno de los escritores favoritos de mi papá, sabía que su ejemplar de "Memoria de Mis Putas Tristes" estaba en su librero y de ahí lo tomé. (Tania, 19 años)

En la casa existen dos ediciones de Cien años de soledad. Una de ellas es la primera edición, aunque ignoro qué número de reimpresión sea. Este libro lo compraron mis padres cuando estaban viviendo en Uruguay, y de ahi que tenga un alto valor sentimental en la biblioteca familiar. (Maury, 33 años).

Es importante destacar el hecho de que la mayoría de las familias de los estudiantes tenían un libro de García Márquez en su biblioteca, aunque no tuvieran una fuerte socialización literaria, les permitió resolver satisfactoriamente la tarea que planteó la profesora con dicho autor, como veremos más adelante.
${ }^{4}$ TAREA INDIVIDUAL SOBRE LA OBRA DE GABRIEL MÁR-

QUEZ

1) Terminar de leer el libro o cuento de Gabriel García Márquez que escogieron

2) Responder las siguientes preguntas sobre su obra:

a) ¿Por qué seleccionaron ese texto?

b) ¿Cómo consiguieron dicho texto, y en qué soporte lo leyeron (libro impreso, PDF, fotocopias, etc)?

c) Hagan un breve resumen de la novela o cuento.

d) ¿Qué personaje les gustó más y cuál menos? Expliquen brevemente la razón.

TAREA GRUPAL SOBRE LA OBRA DE GABRIEL MÁRQUEZ

1) Describan PASO A PASO la búsqueda que realizaron por Internet de las biografías, autobiografías, entrevistas y/o referencias a la obra de Gabriel García Márquez, desde que la iniciaron en clase hasta que culminó en el tarea grupal que presentarán en la siguiente clase.

Expliquen brevemente en cada paso qué seleccionaron y qué descartaron de la información, y por qué.

2) Después de la búsqueda realizada, escriban cuáles son sus impresiones sobre el hombre que escribió la obra, el hombre de carne y hueso que está detrás de sus novelas exitosas.

\section{Gabriel García Márquez "a la carta"}

La profesora del taller de escritura les propuso como tarea individual escoger una novela o un libro de cuentos del autor recientemente fallecido, sin indicarles un soporte o lugar donde conseguirlo ni cómo leerlo, y les dio algunas consignas ${ }^{4}$ para escribir un breve trabajo después de su lectura. La mayoría resolvió la tarea individual de manera bastante convencional: Consiguieron el libro prestado, lo buscaron en las bibliotecas de sus familiares o en la universidad, algunos lo compraron (el más barato y breve), y los menos lo 
leyeron en PDF. Hicieron una lectura tradicional (individual, concentrada y de principio a fin), la mayoría lo leyó completo y en impreso. En los resultados de las tareas se aprecia nuevamente la influencia determinante del capital cultural en la calidad del producto escrito y del nivel de reflexión. En el texto que presentamos a continuación también se puede advertir que no hay nada que nos indique que fue escrito por un estudiante de 18 años, con pleno acceso a la Red y manejo diestro de diversas aplicaciones y programas digitales:

\section{Cólera, amor, y ahora tiempo}

Antonio (18 años)

Desde los 10 años, o tal vez antes porque no recuerdo bien, el libro me atraía mucho. Lo había visto acomodado en un estante dentro del cuarto de mis padres pero jamás habia decidido abrirlo. Ni siquiera tocarlo. (...) El amor en los tiempos de cólera dictaban unas letras negras sobre la tapa y la foto de un hombre sonriente, también de color amarillo, parecía estar saludándome desde la contraportada. "Al parecer se llama Gabriel García" pensé. Claro, a esa edad yo ya entendía qué es el cólera, y tenía cierta noción de qué es el amor. (...) Lo hojeé, lo olí, pero no lo lei ese día, ni ese mismo año. (...) Unos cinco años después, no recuerdo cómo, el libro volvió a mis manos. Sabiendo (o recordando) aún qué es el cólera, y aunque con una noción del amor todavía menos definida que antes, comencé a leerlo. No sé por qué no lo terminé. Desde ese entonces el libro ha estado guardado entre los otros pocos que he comprado y que en ocasiones me he adjudicado tras sacarlos "prestados" de las diminutas bibliotecas de mis padres y de mi abuela. Si no me los apropio los libros van a dar a la basura. Me atrevo a decir que la historia se repite: sé qué es el cólera, el amor sigue confundiéndome, y ahora la cuestión del tiempo me atormenta también. He tomado el libro, lo he abierto, y los tres factores se han reunido desde el momento en que lo he comenzado a releer.

En el marco del mismo taller de escritura, luego la profesora les planteó a los estudiantes una tarea grupal ${ }^{5}$, cuya consigna principal fue "descubrir al hombre de carne y hueso detrás de su obra". Tampoco en esta oportunidad se les dieron indicaciones de cómo, o dónde conseguir la información, pero esta vez sí se puede advertir en sus trabajos, las huellas de su experiencia de lectoescritura en la Red. En los textos elaborados grupalmente, como el ejemplo que se expone a continuación, relatan que utilizan buscadores, orientan las búsquedas con diferentes combinaciones de palabras claves, consultan periódicos como fuente autorizada, miran videos, revisan blogs, y van siguiendo la ruta de los links que cada texto les ofrece. No obstante, en la elaboración posterior de la semblanza (que era el objetivo final de la tarea), ninguno cita las fuentes de donde fue sacada la información. $\mathrm{Y}$ en consecuencia, las referencias originales, que resultaron de volver a compartir lo que ya estaba infinitamente compartido en la Red, perdieron su autoría individual y se diluyeron en el hipertexto:
5 TAREA GRUPAL SOBRE LA OBRA DE GABRIEL MÁRQUEZ

1) Describan PASO A PASO la búsqueda que realizaron por Internet de las biografías, autobiografías, entrevistas y/o referencias a la obra de Gabriel García Márquez, desde que la iniciaron en clase hasta que culminó en el tarea grupal que presentarán en la siguiente clase. Expliquen brevemente en cada paso qué seleccionaron y qué descartaron de la información, y por qué.

2) Después de la búsqueda realizada, escriban cuáles son sus impresiones sobre el hombre que escribió la obra, el hombre de carne y hueso que está detrás de sus novelas exitosas. 


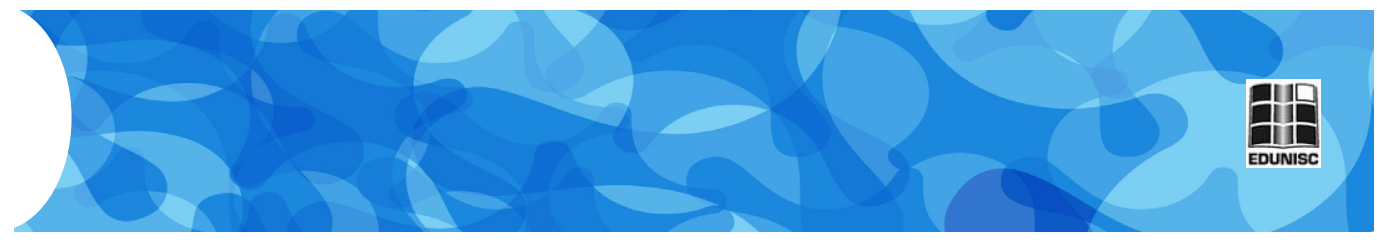

repetir los nombres de las obras del autor, sino rodear esa gran cortina profesional y encontrar al hombre "de carne y hueso" que moldeaba las palabras de tal forma que cautivó al mundo entero. La red de internet que proporciona la UAM era muy débil, por lo que la búsqueda en clase fue nada provechosa y debimos sustituir el ordenador por el libro El Olor de la Guayaba, aunque posteriormente regresamos a la búsqueda en línea. Entramos al buscador de Google e introducimos "García Márquez infancia". Los resultados de búsqueda nos ofrecieron 1.200.000 enlaces relacionados, por lo que no sabiamos por dónde comenzar. Descartamos inmediatamente aquellas páginas cuyo perfil apuntaba a la tradición infame del "copy-paste", y nos dedicamos a buscar articulos que nos ofrecieran anécdotas que pudieran acercarnos más a la intimidad del autor. Consultamos periódicos como El País de España, El Colombiano, El Universal de México, y uno que otro blog que dedica páginas a Gabito. Dentro de las páginas consultadas, el sitio web de la Fundación del Nuevo Periodismo Iberoamericano fue de gran apoyo para conocer al Gabo padre, esposo, vecino, y sobre todo, amigo. (Alejandro, Antonio y Jennifer).

En otra perspectiva, los textos elaborados grupalmente constituyen síntesis expresivas de las diversas negociaciones que se producen en el ámbito escolar entre formas tradicionales y emergentes de lectoescritura en la Red. El primer acuerdo de la negociación estriba en que los estudiantes aprecian lo que la profesora dice y cómo enseña, y ella, por su parte, les permite experimentar y utilizar sus habilidades digitales y de navegación para apoyarse en la resolución de la tarea. El segundo acuerdo tiene que ver con la utilización pragmática y diversificada de todos los recursos al alcance de la mano de los estudiantes. La profesora los deja moverse libremente entre el libro impreso, el PDF, la impresión del PDF, las fotocopias, la dispersión de las búsquedas en Internet, el uso y abuso del hipertexto para comprender y recomponer los textos, pero espera que de toda esa manipulación resulte un texto elaborado y reflexivo donde se citen las fuentes, y no un collage con retazos del copy/paste. Obviamente algunos lo logran y otros no, pero antes de Internet también entregaban tareas que se limitaban a los resúmenes más o menos textuales de los libros, y otras donde se apreciaba una reflexión más lúcida, crítica o creativa. El tercer acuerdo tácito pasa por la comunicación. A la mayoría de estudiantes entrevistados no les preocupa si sus profesores tienen un manejo experto de las redes, pero esperan (y en ocasiones exigen), que la comunicación sea más constante y horizontal y que trascienda obviamente el salón de clases, en síntesis: que estén disponibles todo el tiempo a través del mail o Facebook. El cuarto acuerdo pasa por la tolerancia del uso de los dispositivos digitales en clase. La clase sigue discurriendo de manera predominantemente tradicional con el profesor/a al frente exponiendo los contenidos del curso, y los estudiantes atendiendo, o simulando que atienden. Pero por la vía de la aceptación resignada de la realidad, la mayoría de los profesores cada vez toleran más el uso de los teléfonos inteligentes o tabletas, a sabiendas que la mayoría del tiempo son usadas para comunicarse con los amigos en las redes sociales; pero también, cada vez más, promueven la búsqueda de información puntual sobre algún tema de los que se están 
tratando en la clase, ocasionalmente, o como parte de un ejercicio.

Los acuerdos resultantes - tácitos o explícitos-, de la negociación en el salón de clases entre prácticas tradicionales y emergentes de lectoescritura en la Red, van tejiendo una nueva tela de experiencias en las modalidades de enseñar/aprender y en la comunicación entre estudiantes y profesores, que incorpora lo "nuevo" de manera lenta y pragmática sin descartar lo "viejo". Pero este accidentado y desigual tránsito, no puede ser aún verbalizado en el discurso de los profesores y estudiantes, quienes optan por describir sus prácticas en términos convencionales. Por eso resulta tan compleja y confusa su comprensión. La textura, color y grosor del nuevo lienzo se va redefiniendo en el marco de contradicciones, paradojas, traslapes, redes visibles e invisibles, actores humanos y no humanos, como cualquier otro vínculo histórico y social con las nuevas tecnologías (Dussel, 2015). Lo cual nos obliga como maestros e investigadores, a mantener una actitud reflexiva y abierta sobre nuestras prácticas docentes, y a sostener la vigilancia epistemológica sobre dichas realidades en tanto objetos de estudio. Hoy más que nunca, las preguntas por las condiciones de la producción del conocimiento son obligadas, pero coincidiendo con Latour: "El proyecto general de lo que supuestamente debemos hacer juntos es puesto en duda. El sentido de pertenencia ha entrado en crisis. Pero para registrar esta sensación y seguir estas nuevas conexiones es necesario idear una nueva noción de lo social, no como un dominio especial, un reino específico o un tipo de cosa particular, sino como un movimiento muy peculiar de reasociación y reensamblado" (2008:21).

Por último, la experiencia de observación participante en el taller de escritura muestra que los estudiantes más que abandonar los libros, se han vuelto pragmáticos con ellos. No los rechazan ni los cuestionan, al contrario, siguen teniendo un gran valor simbólico, y si los encuentran o se topan con ellos en alguna de las múltiples carreteras que transitan dentro y fuera de la Red, los leen con gusto, sobre todo si son novelas. Con mayor razón si el encuentro lo propicia un profesor/a, o alguien de su red de afectos significativos. Pero hay algo que los editores de libros tendrían que tener en cuenta en el momento de diseñar sus políticas de ventas: los estudiantes no están dispuestos a pagar por un libro que pueden encontrar dentro o fuera de la Red. Si no lo consiguen prestado (de un familiar, un amigo o la biblioteca), o gratis (libro o PDF), es probable que desistan de leerlo, salvo que sea un texto académico obligatorio. En este caso, si no está disponible en la Red para leer en digital o impreso, buscarán fotocopiarlo, y en último caso, recurrirán a las reseñas, o capítulos dispersos que otros estudiantes escanean y suben a la Red.

El último día del taller la profesora llevó una caja llena de novelas de distintos géneros (algunas clásicas y otras contemporáneas) para regalar a sus estudiantes. Ella pensaba que solo mostrarían interés por el obsequio aquellos que habían estado más comprometidos con las lecturas y tareas del taller. Sin embargo, no dejó de sorprenderla la voracidad que mostraron todos por hacerse con alguno de los libros. No quedó ninguno en la caja. Es difícil saber si los leerán o no, pero si ante una montaña de novelas disponibles todavía manifiestan emoción en llevarse alguna en la mochila junto 
al celular o la tableta, entonces debemos relativizar nuestros más funestos pronósticos sobre la desaparición del libro, y pensar estrategias para acercar los libros al complejo entramado de las autopistas del hipertexto, las imágenes y la navegación en Red. Los estudiantes difícilmente transitarán por su propia iniciativa los viejos caminos y carreteras de la experiencia de la lectura tradicional y unitaria, salvo que alguna de las autopistas se encuentre en reparación, o no sea posible llegar a destino a través de ellas. Y aun así, estas lecturas tradicionales se volverán significativas y trascendentes en las nuevas autopistas, si consiguen aportar algún sentido o valor agregado, explícito o implícito, a la experiencia hipertextual del ensamblaje de cadenas infinitas de material narrativo y audiovisual en la Red.

\section{Una reflexión final}

La recuperación de la perspectiva de los jóvenes en la definición de su experiencia con los textos y soportes impresos y digitales, permite comprender las prácticas tradicionales y emergentes de lectoescritura desde contextos más amplios de producción de significados que son poco abordados en la bibliografía especializada sobre el tema. Los múltiples relatos desplegados en las pantallas necesariamente implican leer y escribir de forma constante, no obstante los jóvenes no lo reconocen de este modo y siguen reservando la definición de lectura y escritura para las actividades que desarrollan en espacios tradicionales y acotados simbólicamente para ese fin, como la universidad, el trabajo escolar o la lectura de novelas, periódicos o revistas. La lectura sigue siendo una actividad cargada de rituales tradicionales: leer es tocar, oler y sentir la textura del papel, leer es dejar huellas y marcas personales en los libros. Leer requiere concentración e intimidad. Leer establece complicidad con el autor, la trama y los personajes. Leer raramente es comprar, es conseguir el libro impreso a través de un amigo, un familiar, o en la biblioteca. La única relación explícita entre leer y la Red, radica en conseguir y bajar gratis un PDF de una novela o libro de texto, para leerlo en pantalla o impreso. Por su parte, en los escenarios virtuales, la experiencia subjetiva de la lectoescritura mientras se está conectado se define como chatear, mensajear, enviar, publicar, mirar, ver, postear, recolectar, escuchar, tuitear, o navegar. Tampoco se lee y se escribe cuando se busca, se googlea, se baja, se linkea, se tuitea, sino que se comparte, en sus propias palabras. Este tipo de prácticas generan un nuevo tipo de capital simbólico que se cultiva y se cosecha en las redes sociodigitales, basado en la acumulación de datos y saberes que no necesariamente se reúnen con la intención de integrarse en cierto orden preconcebido. Metafóricamente hablando, las piezas del rompecabezas no se utilizan para volver a la composición original, sino que se ensamblan con piezas de otros rompecabezas ya reensambladas y compartidas por otros para producir nuevos sentidos de naturaleza necesariamente contingente a partir de condensaciones y desplazamientos sobre el material narrativo original. 
La investigación demuestra claramente que los libros impresos (o las impresiones de los PDF), las fotocopias (como lugar de lectura y escritura) y el uso de los cuadernos y blocks de notas en el salón de clases o en la casa, no han desaparecido del horizonte intelectual de los jóvenes sino que se han resignificado con otros valores agregados. La diferencia radica en que antes constituían un recurso único, indispensable e indiscutible en la formación académica, y ahora están siendo reubicados - a veces íntegros y otras como fragmentos- en una cadena de operaciones cognoscitivas, lúdicas y afectivas en las redes socio digitales, que ya no los tiene como protagonistas de la síntesis, ni de la totalidad del conocimiento, sino como eslabones reciclados de múltiples formas y en diversos formatos en la producción del conocimiento. Lo cual inevitablemente provoca cambios de orden epistemológico, más que de orden ontológico, como bien lo señala Pons (2013:27) "Hemos pensado inútilmente, de manera ingenua, que la revolución tecnológica era simplemente un aumento de las herramientas que tendríamos a nuestra disposición, un incremento de las posibilidades con las que contábamos, como había ocurrido otras veces. Sin embargo, a poco que reparemos en ello entenderemos que la modificación va mucho más allá, pues altera las formas de producción y de comunicación, no el método que nos caracteriza pero sí las prácticas que ejercitamos diariamente (o mejor, no hay variación ontológica, como he apuntado, pero sí epistemológica)"

Las nuevas formas de leer, hipertextuales, hiperreferenciales, hipervinculadas, lejos de empobrecer los viejos saberes, pueden ser el epicentro para una lectura mucho más amplia que involucra elementos, temas, lecturas y soportes novedosos. Lo cual sugiere que la fragmentación, eclecticismo y nomadismo en el manejo y circulación de la información, no llevan necesariamente a la anarquía conceptual sino a una reorganización simbólica que produce un nuevo tipo de experiencia en el espacio biográfico.

Por último, los textos e hipertextos que generan los jóvenes en Internet, nos confirman la importancia que sigue teniendo el capital cultural y simbólico en la calidad de la producción de nuevas síntesis cognoscitivas, como lo demuestra nuestro estudio y otros realizados recientemente (García Canclini, N., Cruces F. y Urteaga M., 2012; Sánchez García, Lluch y Río (2013). En consecuencia, aunque los estudiantes tengan las mismas habilidades digitales, y practiquen operaciones similares con el hipertexto, no todos crean contenidos de igual calidad reflexiva o literaria. Pero esta evidencia tampoco es algo nuevo, más bien sorprende que en el debate entre detractores y defensores de los nuevos modos de leer en la Red, prácticamente no aparezca ninguna referencia al papel que juega el capital cultural en la apropiación de diversos programas y aplicaciones en Internet. Independientemente de las diversas formas de lectoescritura practicadas en cualquier soporte, y aun suponiendo que todos los jóvenes tengan, o puedan adquirir, idénticas habilidades digitales, aquellos con mayor capital cultural y simbólico, realizarán lecturas más comprensivas, elaborarán análisis más reflexivos y producirán textos más creativos.

Respecto a las prácticas de la lectoescritura en la universidad, la dinámica 
del salón de clases se está redefiniendo lentamente a través de diversos tipos de negociaciones entre la experiencia práctica y simbólica de los profesores/ as, por una parte, y la de los estudiantes con los soportes digitales, por otra. Experiencias que no solo están marcadas por diferencias generacionales sino también por su lenta y desigual penetración en el habitus (Bourdieu, 1988) escolar. Lo que queremos destacar es que, aun reconociendo las diferencias entre las habilidades y competencias digitales de unos y otros (que ya no son tantas ni tan marcadas), el conjunto de disposiciones y actitudes que forjaron históricamente el habitus escolar, sigue determinando en buena medida las modalidades de enseñanza/aprendizaje en la universidad. En otras palabras, la incorporación de las nuevas habilidades digitales que repercuten en formas emergentes de lectoescritura en la Red, avanzan mucho rápido en transformar la experiencia personal de los/las profesores/as y alumnos/as, que lo que consiguen impactar en la dinámica pedagógica del salón de clases:

\begin{abstract}
"En general no es fácil atravesar las fronteras de la escuela. La fuerza de lo instituido desde hace siglos es considerable y suele constituir una barrera que protege a la escuela de cambios que suceden fuera de ella. Los contenidos que se han cristalizado como enseñables - los que son efectivamente enseñados, en particular aquellos que en la práctica resultan prioritarios ya que se les dedica mucho tiempo escolar-, así como las formas arraigadas de presentarlos, contribuyen a hacer invisibles otras posibilidades o entran en conflicto con las transformaciones que se aspira a producir para acercar el universo escolar al extraescolar" (Lerner, 2012: 31-32)
\end{abstract}

No obstante, la lógica hegemónica del espacio escolar, y la lógica emergente del espacio virtual, no se comportan como ámbitos totalmente separados en la experiencia cotidiana de la lectoescritura de los jóvenes, sino más bien que entre ambas se producen cruces, traslapes y negociaciones de carácter afectivo, cognoscitivo y pragmático. Los estudiantes declaran sistemáticamente que prefieren los libros impresos y las fotocopias para leer y comprender mejor los textos, y que también optan por el papel para resumir, organizar, esquematizar, y personalizar las ideas, pero en sus prácticas se observa el uso pragmático de todas las plataformas, soportes y recursos físicos y digitales para resolver los trabajos universitarios y la negociación, más que el conflicto, entre prácticas tradicionales y emergentes de lectoescritura dentro y fuera del salón de clases.

\title{
Bibliografía citada
}

ALBARELLO, F. (2011). Leer-navegar en internet: las formas de lectura en la computadora. La Crujía, Buenos Aires.

ANDRADE, L. (2007). "Leer: laboriosa construcción de una práctica y los desafíos de la cibercultura". En Revista Iberoamericana de Educación. N ${ }^{\circ}$ 43/2. 10 junio 2007. OEI. 


\section{Trioma}

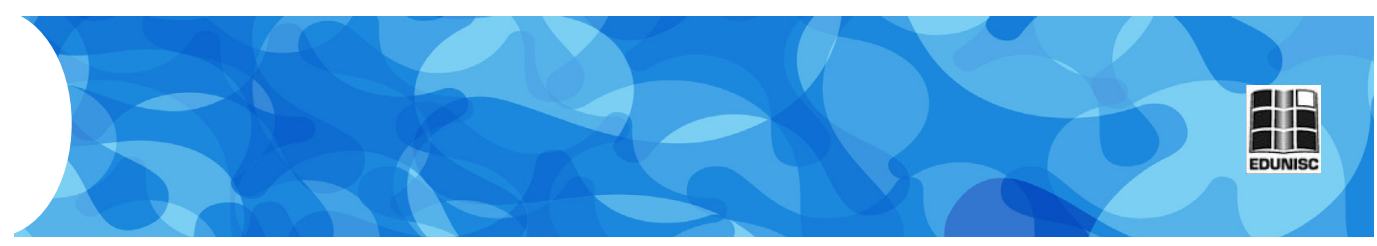

CASTELLANOS, Ribot Margarita (2011). "Literacidad: prácticas de lectura de impresos y electrónica de los alumnos de la carrera de Comunicación Social de la UAM-X”. En Seminario de Lectura en el mundo de los jóvenes ¡Una actividad en riesgo! Coordinador por Elsa M. Ramírez Leyva. México. CUIB. UNAM.

CHARTIER, R. (1997). "Las representaciones de lo escrito". En Estudios Sociales, Revista Universitaria Semestral, Año VII, No. 13. Argentina, P.130. Disponible en: http://bibliotecavirtual.unl.edu.ar/ojs/index.php/EstudiosSociales/article/viewFile/2389/3409

CHARTIER, R. (2010), “Aprender a leer, leer para aprender". en Nuevo mundo, mundos nuevos, Debates. No. 10. 01 de febrero de 2010. Disponible en: http://nuevomundo.revues.org/58621

DOMÍNGUEZ, M. y RODRÍGUEZ, S. (2005). "Transformaciones en las prácticas culturales de los jóvenes. De la lectura como ocio y consumo de fragmentación neotecnológica”. En Revista de Estudios de juventud No. 70. Jóvenes y lectura.

DUSSEL, I. (2012). "Más allá del mito de los "nativos digitales". Jóvenes, escuelas y saberes en la cultura digital", en: Southwell, M. (comp.). Entre generaciones. Exploraciones sobre educación, cultura e instituciones. Rosario, FLACSO/Homo Sapiens. Pp.. 183-213.

DUSSEL, I. (2015). "Nuevas alfabetizaciones en la escuela. La educación escolar y los saberes en la era digital". Pereyra, M. (comp.), Los multialfabetismos en las sociedades del conocimiento, Granada, Ed. Aljibe. (en prensa).

GARCÍA CANCLINI, N., CRUCES F. y URTEAGA M (compiladores.) Jóvenes, culturas urbanas y redes digitales (2012). Ariel/UAM/Teléfonica/ UNED.

IGARZA, R. (2011). "El libro-pantalla: los contenidos digitales y el futuro de la lectura". En La Sociedad de las cuatro pantallas, una mirada latinoamericana. Coord. Silvia Spadaccini. Fundación Telefónica, Ariel. 81-102 pp.

LATOUR, B. (2008) Reensamblar lo social. Una introducción a la teoría del actor- red. Editorial Manantial, Buenos Aires.

LERNER, D. (2012) "La incorporación de las TIC en el aula. Un desafío para las prácticas escolares de lectura y escritura" en Goldin, Kriscautzky y Perelman (coordinadores) Las TIC en la escuela, nuevas herramientas para viejos y nuevos problemas. Océano Travesía. México. 


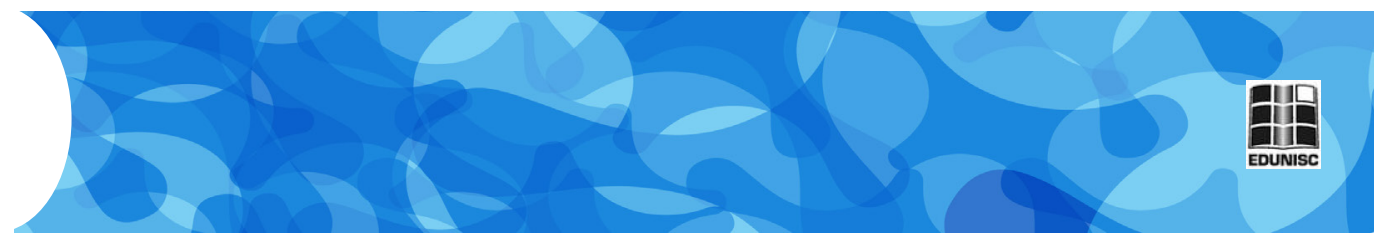

PONS, A. (2013) El desorden digital. Guía para historiadores y humanistas, Madrid, España

REY, G. (2009) "Las reubicaciones de la lectura. Libros, lectores y lecturas. En Pensamiento Iberoamericano No. 4. Pp.235-253.

SÁNCHEZ GARCÍA, S., LLUCH G. y DEL RÍO, T (2013) "La lectura en la web 2.0. Estudio de caso: los Blogs en el Reto Delirium. @ atic.Revista d'innovació educativa, 10. Valencia: Universitat de Valencia. 